\title{
Displaced Radial Neck Fractures in the Paediatric Age Group Fixed with the Modified Metaizeau Technique: Experience of a Tertiary Care Hospital in Northern India
}

\author{
Rajeev Kumar Kansay ${ }^{1}$ Siddharth Kothari', Ashwani Soni ${ }^{1} \quad$ Rohit Jindal ${ }^{1} \quad$ Sudhir Kumar Garg ${ }^{1}$ \\ Sumukh Shail ${ }^{1}$
}

${ }^{1}$ Department of Orthopaedics, Government Medical College and Hospital, Chandigarh, India

Address for correspondence Rajeev Kumar Kansay, Department of Orthopaedics, Government Medical College and Hospital, Chandigarh, India (e-mail: drkansay@yahoo.co.in).

Int J Recent Surg Med Sci 2022;8:33-38.

\begin{abstract}
Keywords

- metaizeau technique

- radial neck

- judet classification

Background Radial neck fractures in the pediatric population represent up to one percent of all pediatric fractures. Judet type III and IV radial neck fractures present difficulties in closed and open reduction. The Metaizeau technique has been used as a tool to reduce these. We present a case series of 17 patients with Judet III and IV type of radial neck fractures treated with a modified Metaizeau technique.

Materials and Methods Seventeen patients, eight male and nine female with Judet type III and IV radial neck fractures over a two-year period were managed with modified Metaizeau technique as described in the text. The follow up period in our Prospective Interventional study was of six months The outcomes were scored using the Mayo elbow Performance score.

Results Fourteen patients had excellent scores, and three had good scores. Union rate was $100 \%$. Fourteen patients were managed with closed reduction using the modified Metaizeau technique. Three patients required additional Open reduction, out of which one had reduced ROM as an outcome at the end of six months.

Conclusion The modified Metaizeau technique is an extra articular, easy to learn procedure with good to excellent results in Judet type III and IV radial neck fractures.
\end{abstract}

\section{Introduction}

Fractures of the radial neck constitute up to five percent of injuries around the elbow. These represent one percent of all pediatric fractures. ${ }^{1}$ The peculiar vascular anatomy of the radial head and neck makes it a zone with a precarious blood supply. The radial head is covered by articular cartilage, and vessels enter at level of periosteal attachment. These get damaged at the time of injury and open manipulation. Complications range from stiffness, malunion, osteonecrosis, and nerve injury. ${ }^{2}$ These go up to $36 \%$ as per recent literature. ${ }^{3,4}$ Long term sequelae with deformity like cubitus valgus and reduced pronation are of concern as well. ${ }^{5}$
DOI https://doi.org/ $10.1055 / \mathrm{s}-0041-1735441$ ISSN $2455-7420$ (c) 2021. Medical and Surgical Update Society.

This is an open access article published by Thieme under the terms of the Creative Commons Attribution-NonDerivative-NonCommercial-License, permitting copying and reproduction so long as the original work is given appropriate credit. Contents may not be used for commercial purposes, or adapted, remixed, transformed or built upon. (https://creativecommons.org/licenses/by-nc-nd/4.0/).

Thieme Medical and Scientific Publishers Pvt. Ltd. A-12, 2nd Floor, Sector 2, Noida-201301 UP, India 
Proper management hinges in the assessment of angulation of the fracture fragment. Commonly utilized Judet classification has been instrumental in planning the treatment. ${ }^{6}$ (- Table 1). Judet III and Judet IV are not considered amenable to closed reduction. Operative options are broadly grouped under closed reduction, ${ }^{7,8}$ Open reduction, ${ }^{7,9}$ percutaneous K-wire fixation, ${ }^{7,10}$ and intramedullary fixation with K-wires. , $^{70,11}$

The Metaizeau technique is a method of non-invasive manipulative reduction initially described for pediatric radial neck fractures in $1980 .{ }^{11}$ We are sharing our experience in a case series of 17 pediatric radial neck fractures managed with the modified Metaizeau technique, which is usually used for type III and IV Judet fractures by levering out of fractured fragment with help of K-wire, which makes it different from conventional Metaizeau technique. ${ }^{12}$

\section{Materials and Methods}

The Prospective study was approved by the Institutional review board. All 17 cases presented to the emergency department from April 2018 to April 2020. Anteroposterior and lateral X-ray views of the involved elbow were done. Temporary immobilization was given in the form of above elbow slab support.

Angulation of the fracture was calculated between two lines passing through the radial axis and the fracture fragment on the radiograph as shown in - Fig. 1. Patients were then classified according to the Judet classification of radial neck fractures as mentioned in - Table 1. Appropriate consents using a standard preforma were taken and patients were planned for operative management.

In the operation theater: After getting the angulation in both AP and Lateral view X-ray of the The elbow as shown in - Figs. 1 and 2, the involved upper limb was painted and draped under aseptic precautions. Longitudinal traction was applied with the involved forearm supinated to align the fracture by closed means. A Titanium elastic nail of diameter 1.5-2.0 mm was taken.

Entry point was made with an awl made $4 \mathrm{~cm}$ proximal to the distal physis using Image intensifier in both AP and Lateral view. The Titanium elastic nail was introduced into the medullary canal and checked under image intensifier. It was passed upwards across the canal till it abutted the

Table 1 Judet classification ${ }^{6}$

\begin{tabular}{|c|l|}
\hline \multicolumn{2}{|l|}{ Judet Classification of Radial Neck Fractures } \\
\hline Type & Description \\
\hline 1 & $\begin{array}{l}\text { Non displaced or Horizontal shift of } \\
\text { Epiphysis }\end{array}$ \\
\hline 2 & $<30$ Degree Angulation \\
\hline 3 & $30-60$ Degree Angulation \\
\hline $4($ a) & $60-80$ Degree Angulation \\
\hline $4(b)$ & $\begin{array}{l}>80 \text { Degree Angulation or Complete } \\
\text { Dislocation of } \\
\text { Epiphysis }\end{array}$ \\
\hline
\end{tabular}

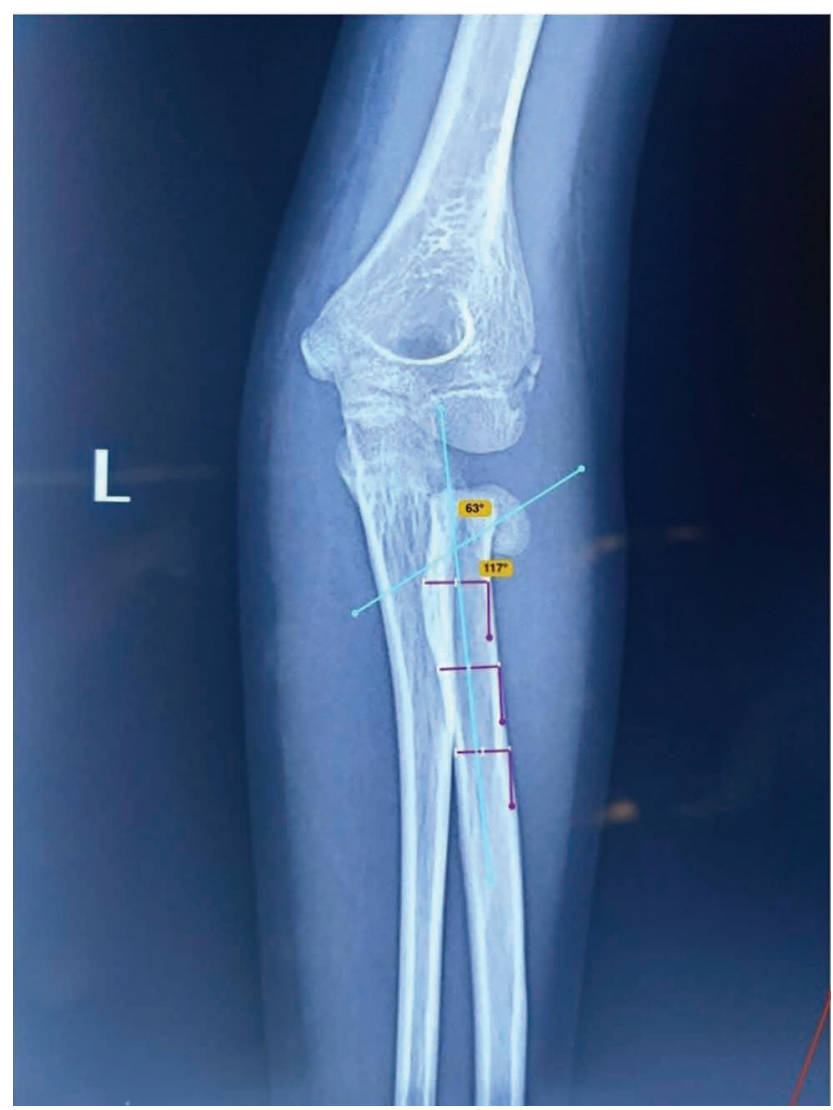

Fig. 1 AP View $X$-rays showing initial angulation of the fracture.

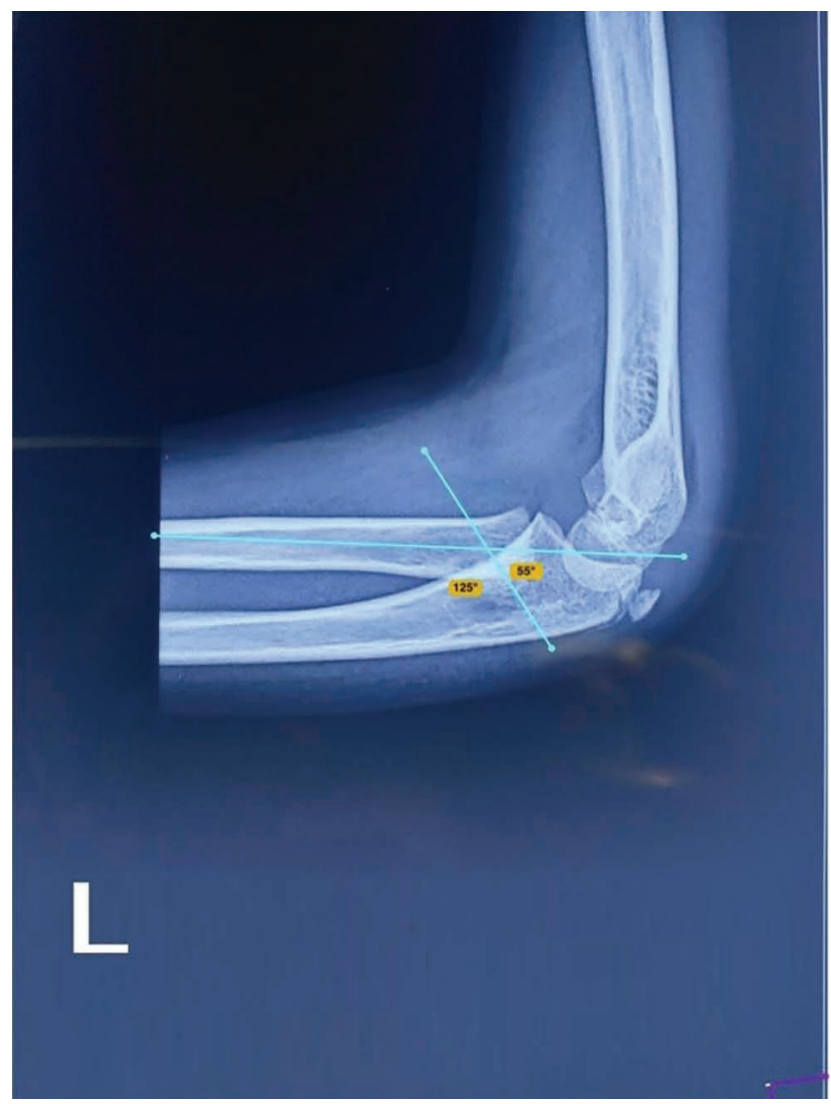

Fig. 2 Lateral View X-rays showing initial angulation of the fracture. 
fractured fragment. By Levering on the fractured fragment with the K-wire as shown in - Fig. 3, the fragment was lifted from its angulated position to its normal position as shown in - Fig. 4. In cases with angulation above 80 degrees K-wire assisted reduction was done. With gentle tapping using the mallet, it was fixed to the fractured fragment at the point of maximum tilt. After appropriate leverage, the Titanium elastic nail was turned 180 degrees to restore the fragment to its original position. Final reduction was confirmed with the $\mathrm{C}$-arm in both AP and Lateral views. The lower end of the nail is then cut and bend. Patient was immobilized in splint for two weeks, after which the elbow was mobilized. After complete fracture healing as shown in - Fig. 5, Titanium elastic nail was removed at the end of six months.

Bony Union was assessed on follow up visits, utilizing repeat X-rays of the elbow in Anteroposterior and lateral view. The X-rays were evaluated for maintained reduction of the fragment, and union of the fracture as shown by the filling up of the fracture line. Clinical assessment with range of elbow movements was also done.

At the end of six month follow up, this data was compiled according to the Mayo elbow performance score and was tabulated for each patient respectively. The data was then assessed statistically. Correlation using the Spearmen coefficient was calculated between the Final Mayo score and the initial fracture angulation, as well as the method of our reduction. The correlation between the type of reduction and the Mayo score was studied using the Mann-Whitney test.

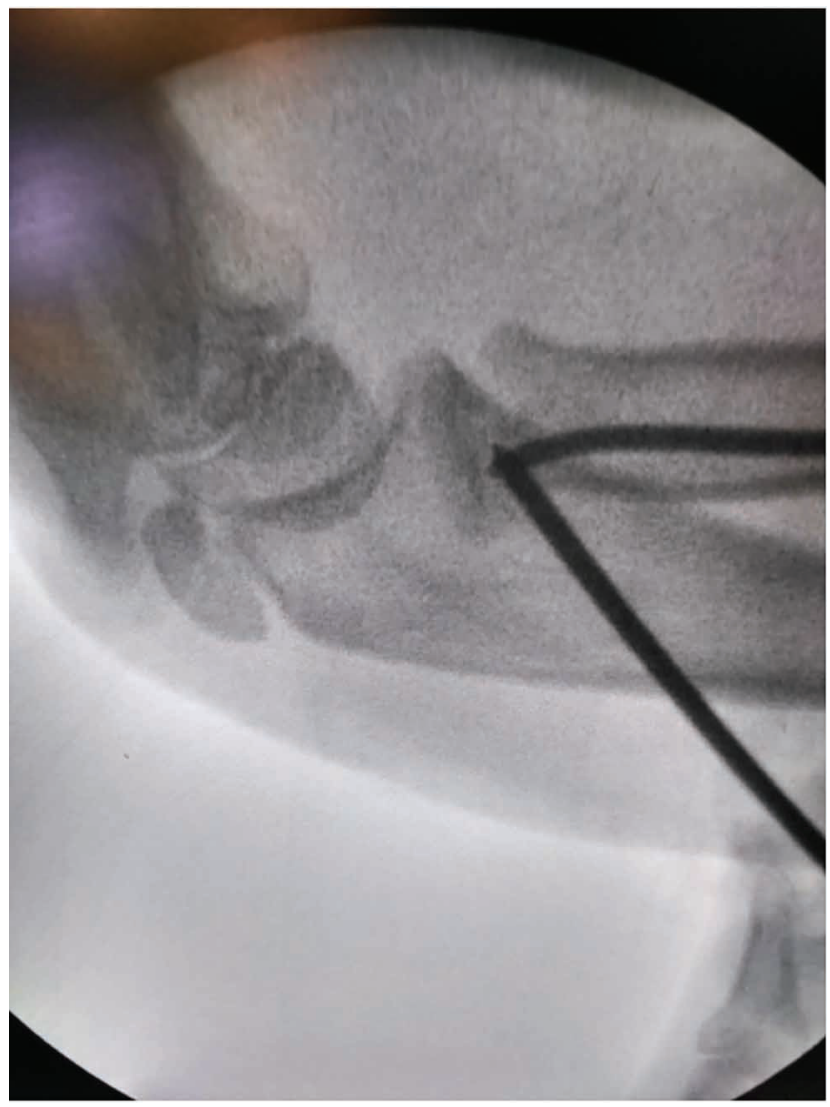

Fig. 3 Elevation of the fracture fragment levering the nail.

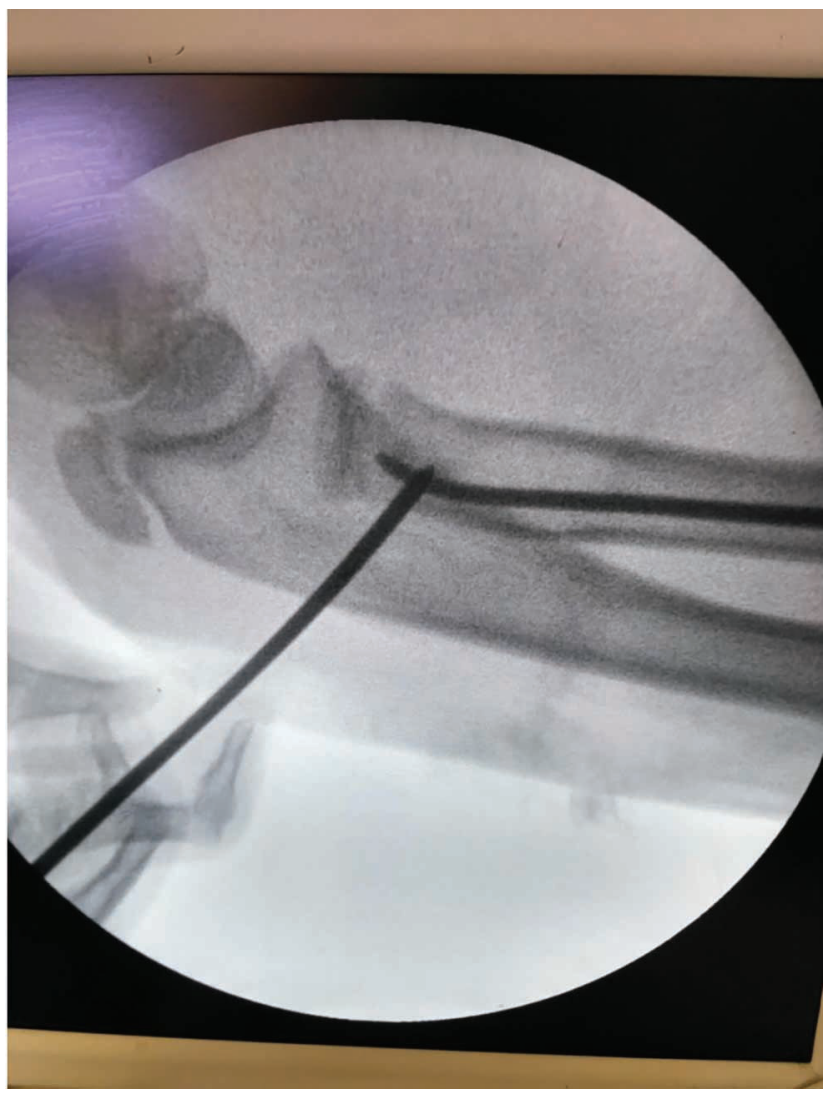

Fig. 4 Fracture reduced with nail in situ.

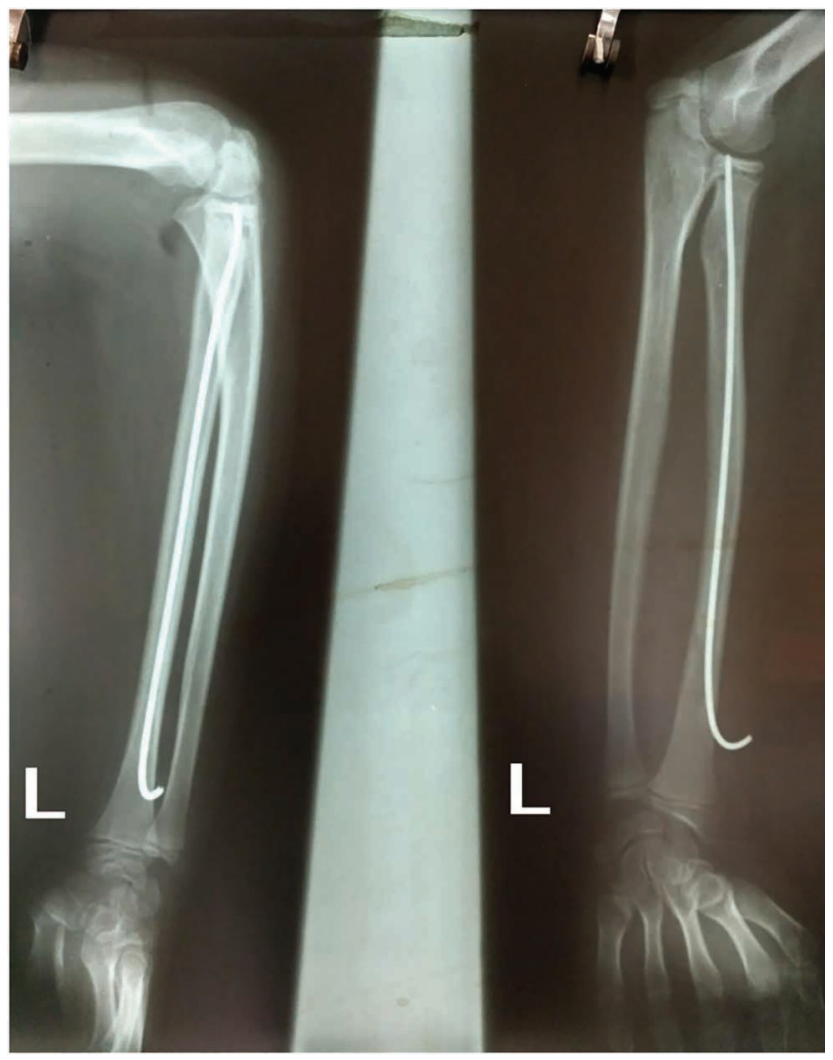

Fig. $5 \mathrm{AP}$ and Lateral X-ray of the forearm and elbow at 6 months follow up. 


\section{Results}

There were seventeen patients in total, ranging from $8-13$ years old. The average age was $10+/-1.5$ years. Eight cases $(46.1 \%)$ involved the left side, and nine cases (52.9\%) were of the right side. Seven patients $(41.2 \%)$ were males, and ten (58.8\%) were females.

There was a strong positive correlation between Fracture Angulation (Degrees) and Age (Years), and this correlation was statistically significant ( $\mathrm{rho}=0.64, p=0.006$ ).

There was a moderate negative correlation between Mayo Elbow Performance Score and Age (Years), and this correlation was not statistically significant ( $r h o=-0.48, p=0.052$ ).

The mean of Fracture Angulation in the Male group was $62.43+/-10.52$. The mean of Fracture Angulation in the female group was $50.00+/-10.02$. There was no significant difference between the groups in terms of Mayo Elbow Performance Score $(\mathrm{W}=24.000, p=0.167)$.

There was a significant difference between the 2 groups in terms of fracture angulation, studied using the Wilcoxon-Mann-Whitney U Test $(\mathrm{W}=61.500, p=0.011)$, with the median fracture angulation being highest in the male group. Similarly, fracture angulation and sidedness was studied and found to have no significant correlation. $(\mathrm{W}=34.500, p=0.923)$

Thirteen (76.5\%) of the participants had Judet Grade injury. Four (23.5\%) of the participants had Judet Grade 4 fracture. The patients with Judet type 3 injuries fared better as compared with the type 4 patients. $(\mathrm{W}=52.000, \mathrm{p}=<0.001$ )

Sidedness had no impact on the final Mayo score. $(\mathrm{W}=$ $36.000, p=1.000$ ).
None of the cases had any associated injuries at presentation. All cases were followed for a minimum of six months to one year. Union was $100 \%$ at end of the six month follow up. Patient data are mentioned in - Table 2.

In our series, 13 patients had initial angulation of between 30-60 degrees. Mean angulation was 55.12+/-11.74. The assessment for function was done using the Mayo elbow performance score. ${ }^{13}$ The components of the score include assessments of Pain, Motion, Stability and Function. The maximum possible score is 100 . Scores above 90 are considered as an excellent result. Scores from 75-89 are good, 60-74 are fair, and below 60 are evaluated as poor. Thirteen patients (76\%) had a Mayo score of 100 , three patients (18\%) had score of 85 and one patient (6\%) had a Mayo score of 95. The mean Mayo elbow score was 97.06+/- 5.88.

There was a strong negative correlation between Mayo Elbow Performance Score and Fracture Angulation (Degrees), and this correlation was statistically significant (rho $=-0.75$, $\mathrm{p}=<0.001)$.

For every 1 unit increase in Fracture Angulation (Degrees), the Mayo Elbow Performance Score decreased by 0.43 units.

Three patients had an initial angulation of between 60-80 degrees, which required Open reduction. One patient had initial angulation above 80 degrees, requiring Open reduction, and eventually had a decreased elbow ROM at six month follow up.

Three patients (17\%) of the series required Open reduction. Rest all were managed with a closed procedure. One patient had decreased Range of Motion as a complication. No other complications were noted in any other case.

Table 2 Patient data with outcome measures

\begin{tabular}{|c|c|c|c|c|c|c|}
\hline Serial No. & $\begin{array}{l}\text { Age } \\
\text { (Years) }\end{array}$ & Sex & Side & $\begin{array}{l}\text { Fracture } \\
\text { Angulation } \\
\text { (Degrees) }\end{array}$ & $\begin{array}{l}\text { Mayo Elbow } \\
\text { Performance } \\
\text { Score }\end{array}$ & Reduction \\
\hline 1 & 8 & Female & Left & 53 & 100 & Close \\
\hline 2 & 12 & Male & Left & 68 & 85 & Open \\
\hline 3 & 9 & Female & Right & 47 & 100 & Close \\
\hline 4 & 10 & Female & Right & 49 & 100 & Close \\
\hline 5 & 12 & Male & Left & 57 & 100 & Close \\
\hline 6 & 11 & Male & Right & 82 & 85 & Open \\
\hline 7 & 10 & Female & Left & 38 & 100 & Close \\
\hline 8 & 11 & Female & Right & 55 & 100 & Close \\
\hline 9 & 8 & Female & Right & 47 & 100 & Close \\
\hline 10 & 9 & Male & Left & 67 & 95 & Close \\
\hline 11 & 9 & Female & Right & 39 & 100 & Close \\
\hline 12 & 11 & Male & Right & 55 & 100 & Close \\
\hline 13 & 10 & Female & Left & 51 & 100 & Close \\
\hline 14 & 9 & Male & Left & 55 & 100 & Close \\
\hline 15 & 8 & Female & Left & 47 & 100 & Close \\
\hline 16 & 13 & Female & Right & 74 & 85 & Open \\
\hline 17 & 10 & Male & Right & 53 & 100 & Close \\
\hline
\end{tabular}




\section{Discussion}

There are several options for the management of radial neck fractures in the pediatric age group. Closed reduction may be difficult in fractures with increased angulation. There may also be loss of reduction associated with the same. ${ }^{14}$ Open reduction has been known to have its own set of complications. ${ }^{2,713}$ The elastic stable Intramedullary nailing technique, described by Metaizeau has been known to involve extra articular manipulation is less invasive and has a smaller learning curve. It has a lower rate of complications as well. ${ }^{14}$

A 2009 paper by Klitscher et al evaluated 28 radial neck fractures of Judet III and IV types. ${ }^{15} 24$ were managed with the Metaizeau technique. The cases were followed up for 32 weeks. The Mayo elbow performance score was utilized to assess the outcomes. $82 \%$ reported excellent outcomes. Remaining had good outcomes. Three patients reported malunion, in the form of angulation of more than 20 degrees. No other major complications were noted.

Our study had 76\% excellent outcomes amongst seventeen patients. We reported no complications.

In a study by P Gupta et al, fourteen children were treated with modified Metaizeau technique..$^{12}$ All of the patients had Judet type IV fracture of radial neck with mean angulation of $72.8^{\circ}$.The average follow-up was 39 months. Heterotrophic ossification and transient posterior interosseous nerve palsy were the only complication seen in two patients who had to undergo open reduction.

Mean angulation in our study was $55.12+/-11.74$. Although we had a shorter follow up period of six months, we reported no complications. Open reduction group in our study, although had significantly lesser Mayo scores, still did not have any complications as mentioned above.

The Mayo score was utilized for assessment, and they obtained 100\% excellent clinical outcome. Our Operative method was similar to them, with a distally based entry to protect the superficial radial nerve. As injury to the nerve has been noted in previous studies with the conventional Metaizeau technique, we advise on utilizing this entry point for the fixation.

Functional arc for forearm rotations is defined as pronation of 50 degrees and supination of 50 degrees. Klitscher et al assessed rotations, and found them to be functionally well restored after treatment with the Metaizeau technique. ${ }^{15}$ We found elbow ROM to be functionally restored in 16 patients. One patient had decreased range of movements as a complication.

Poor outcomes with radial neck fractures are attributable to severe initial angulation, improper reduction, and complications of open reduction..$^{15}$ The presence of associated injuries does influence the outcome. These range from elbow dislocations, olecranon fractures and fractures of apophysis. ${ }^{2}$ In our case series, there were no associated injuries at presentation.

Fracture angulation has long been utilized as a means to plan management. It has been observed that when the initial angulation is below 80 degrees, the reduction was stable and gave results ranging from good to excellent. Studies by
Metaizeau et al, and Gonzalez et al pointed out that when the initial reduction exceeded 80 degrees, there was good outcome in $75 \%$ cases. The remaining required open reduction. ${ }^{14,16}$ In our study, angulation above 60 degrees was seen in $18 \%$ patients. The increased initial angulation does not allow easy reduction utilizing a closed procedure. The Open reduction is required in these cases and may affect the final ROM.

In Judet type IV fractures, Metaizeau et al described poorer outcomes. ${ }^{11}$ In those fractures, closed intramedullary pinning delivered $74 \%$ excellent results and $23 \%$ bad results, and open reduction resulted in $25 \%$ excellent and $45 \%$ bad results.

In our case series, thirteen patients had Judet type III fractures, and four patients had Judet type IV fractures. $82 \%$ patients had excellent results. The remaining had good results. Excellent result was noted in $100 \%$ patients operated with closed reduction. Good result was noted in all the patients operated with Open reduction. We also found Judet type IV fractures to have a worse outcome than Type III injuries. Open reduction had significantly lower Mayo scores than closed reduction group.

\section{Conclusion}

The modified Metaizeau technique is a closed, minimally invasive, extra articular technique with good to excellent results in the pediatric age group in cases of Judet type III and IV radial neck fractures with angulation.

\section{Conflict of Interest}

None declared.

\section{References}

1 Prathapkumar KR, Garg NK, Bruce CE. Elastic stable intramedullary nail fixation for severely displaced fractures of the neck of the radius in children. J Bone Joint Surg Br 2006;88(3):358-361

2 Weinberg AM, Tscherne $\mathrm{H}$, Unfallchirurgie im Kindesalter. Berlin, PA: Springer; 2006

3 Zimmerman RM, Kalish LA, Hresko MT, Waters PM, Bae DS. Surgical management of pediatric radial neck fractures. J Bone Joint Surg Am 2013;95(20):1825-1832

4 Basmajian HG, Choi PD, Huh K, Sankar WN, Wells L, Arkader A. Radial neck fractures in children: experience from two level-1 trauma centers. J Pediatr Orthop B 2014;23(4):369-374

5 Métaizeau JP. Reduction and osteosynthesis of radial neck fractures in children by centromedullary pinning. Injury 2005;36(Suppl 1) :A75-A77

6 Judet J, Judet R, Lefranc J. [Fracture of the radial head in the child]. Ann Chir 1962;16:1377-1385

7 Chambers HG, Fractures of the proximal radius and ulna. In: Beaty JH, Kasser JR, eds. Fractures in Children. Philadelphia, PA: Lippincott Williams and Wilkins; 2001 483-528

8 Neher CG, Torch MA. New reduction technique for severely displaced pediatric radial neck fractures. J Pediatr Orthop 2003;23(5):626-628

9 Steinberg EL, Golomb D, Salama R, WientroubS. Radial head and neck fractures in children. J Pediatr Orthop 1988;8(1):35-40

10 Steele JA, Graham HK. Angulated radial neck fractures in children. A prospective study of percutaneous reduction. J Bone Joint Surg Br 1992;74(5):760-764 
11 Metaizeau JP, Prevot J, Schmitt M. Réduction et fixation des fractures et décollements épiphysaires de la tête radiale par broche centromédullaire. Revue de Chirurgie Orthopedique et Reparative de L'appareil Moteur 1980;66:47-49

12 Bither N, Gupta P, Jindal N. Pediatric displaced radial neck fractures: retrospective results of a modified Metaizeau technique. Eur J Orthop Surg Traumatol 2015;25(1):99-103

13 Tibone JE, Stoltz M. Fractures of the radial head and neck in children. J Bone Joint Surg Am 1981;63(1):100-106

14 Metaizeau JP, Lascombes P, Lemelle JL, Finlayson D, Prevot J. Reduction and fixation of displaced radial neck fractures by closed intramedullary pinning. J Pediatr Orthop 1993;13(3):355-360

15 Klitscher D, Richter S, Bodenschatz K, et al. Evaluation of severely displaced radial neck fractures in children treated with elastic stable intramedullary nailing. J Pediatr Orthop 2009;29(7):698-703

16 González-Herranz P, Alvarez-Romera A, Burgos J, Rapariz JM, Hevia E. Displaced radial neck fractures in children treated by closed intramedullary pinning (Metaizeau technique. J Pediatr Orthop 1997;17(3):325-331 